\title{
Magnetic properties of Mn doped ZnO tetrapod structures
}

\author{
V. A. L. Roy \\ Department of Electrical \& Electronic Engineering, University of Hong Kong, Pokfulam Road, \\ Hong Kong
}

A. B. Djurišića)

Department of Physics, University of Hong Kong, Pokfulam Road, Hong Kong

H. Liu and X. X. Zhang

Department of Physics, Hong Kong University of Science and Technology, Clearwater Bay, Hong Kong

Y. H. Leung, M. H. Xie, and J. Gao

Department of Physics, University of Hong Kong, Pokfulam Road, Hong Kong

H. F. Lui and C. Surya

Department of Electronic and Information Engineering, Hong Kong Polytechnic University, Hung Hom, Kowloon, Hong Kong

(Received 29 July 2003; accepted 4 December 2003)

\begin{abstract}
$\mathrm{ZnO}$ tetrapod nanostructures were prepared by evaporating $\mathrm{Zn}$ metal under humid argon flow. After the fabrication, Mn diffusion doping was performed at two different temperatures $\left(600\right.$ and $\left.800^{\circ} \mathrm{C}\right)$. The samples were characterized by scanning electron microscopy, transmission electron microscopy, x-ray fluorescence, x-ray diffraction (XRD), superconducting quantum interference device magnetometer, and photoluminescence. Diffusion doping resulted in the increase of the size of tetrapods, but no new peaks were found in XRD spectrum. Mn doped $\mathrm{ZnO}$ tetrapod structures were found to be ferromagnetic with Curie temperature $\sim 50 \mathrm{~K}$, and showed large coercive field ( $\sim 3500$ Oe for $800^{\circ} \mathrm{C}$ sample, $\sim 5500$ Oe for $600{ }^{\circ} \mathrm{C}$ sample). (C) 2004 American Institute of Physics. [DOI: 10.1063/1.1645312]
\end{abstract}

Due to its wide band gap $(3.37 \mathrm{eV})$ and large exciton binding energy $(60 \mathrm{meV}), \mathrm{ZnO}$ is of great interest for photonic applications and its optical properties have been studied in detail. In recent years, due to prediction of possible ferromagnetic properties in transition metal doped $\mathrm{ZnO}$ with Curie temperature $\left(T_{c}\right)$ above room temperature, ${ }^{1,2}$ studies of transition metal doped $\mathrm{ZnO}$ have been attracting lots of attention. Theoretical calculations predict that $\mathrm{Mn}$ doped $p$-type $\mathrm{ZnO}$ should be ferromagnetic at room temperature. ${ }^{1,2}$ In the absence of $p$-type doping, theoretical calculations predict that $\mathrm{Mn}$ doped $\mathrm{ZnO}$ would exhibit antiferromagnetic properties. ${ }^{2}$ There have been several experimental works on transition metal doping of $\mathrm{ZnO}$ thin films. ${ }^{3-7}$ The obtained results have been contradictory. Paramagnetic properties were reported for $\mathrm{Zn}_{0.93} \mathrm{Mn}_{0.07} \mathrm{O}$ films prepared by magnetron sputtering. ${ }^{4}$ Antiferromagnetic behavior was observed in $\mathrm{Zn}_{0.64} \mathrm{Mn}_{0.36} \mathrm{O}$ films prepared by pulsed laser deposition ${ }^{7}$ and polycrystalline $\mathrm{ZnO}: \mathrm{Mn}$ powder samples. ${ }^{5}$ However, ferromagnetism was reported in $\mathrm{Mn}$-implanted $\mathrm{ZnO}: \mathrm{Sn}$ single crystals $\left(T_{c} \sim 250 \mathrm{~K}\right)^{6}$ and $\mathrm{Zn}_{1-x} \mathrm{Mn}_{x} \mathrm{O} \quad(x=0.1$ and $x$ $=0.3$ ) films prepared by laser molecular beam epitaxy. ${ }^{3}$ Most likely the differences in the reported results are due to different preparation methods, since the properties of $\mathrm{ZnO}$ are sensitive to the preparation conditions. The previously reported studies focus on magnetic properties of Mn doped thin films, powders and single crystals.

Different shapes of $\mathrm{ZnO}$ nanostructures, such as

\footnotetext{
${ }^{a)}$ Author to whom correspondence should be addressed; electronic mail: dalek@hkusua.hku.hk
}

nanoribbons, ${ }^{7}$ nanowires, ${ }^{8,9}$ and tetrapod nanorods,,${ }^{10-13}$ were reported. In our recent work, we reported synthesis of $\mathrm{ZnO}$ tetrapod nanorods and nanowires under different gas flow. ${ }^{13}$ The fabrication of $\mathrm{ZnO}$ nanostructures was performed in humid argon flow as reported previously. ${ }^{13}$ Diffusion doping was performed by placing $0.654 \mathrm{~g}$ of $\mathrm{ZnO}$ nanostructures and $0.054 \mathrm{~g}$ of $\mathrm{Mn}$ in the tube furnace at the desired temperature $\left(600\right.$ or $\left.800^{\circ} \mathrm{C}\right)$. The quartz process tube was then connected to a vacuum pump and diffusion was performed for $30 \mathrm{~min}$. The structure of the obtained material was investigated by x-ray diffraction (XRD) using a Siemens D5000 $\mathrm{x}$-ray diffractometer, scanning electron microscopy (SEM) using Cambridge-440 SEM, and transmission electron microscopy (TEM) using Philips Tecnai 20 TEM. Magnetic properties were studied using a superconducting quantum interference device (SQUID) magnetometer (MPMS-5s). The Mn content was determined using x-ray fluorescence (XRF) spectrometer JEOL JSX-3201Z. The room temperature photoluminescence was measured using a $\mathrm{HeCd}$ laser excitation source $(325 \mathrm{~nm})$.

Figure 1 shows the representative SEM images of $\mathrm{ZnO}$ nanostructures before and after Mn diffusion doping. Before the diffusion doping, the sample consists of a mixture of $\mathrm{ZnO}$ tetrapod structures with nanowires growing out of tetrapod legs [see Fig. 1(a)]. After Mn diffusion doping, the size of the tetrapods increases as expected (but the leg diameter remains in submicron range). In some cases, structures with broadened tetrapod centers can be observed, as shown in Fig. 1(b). Obtained morphologies after Mn diffusion are very similar for 600 and $800^{\circ} \mathrm{C}$. Longer diffusion time (not 

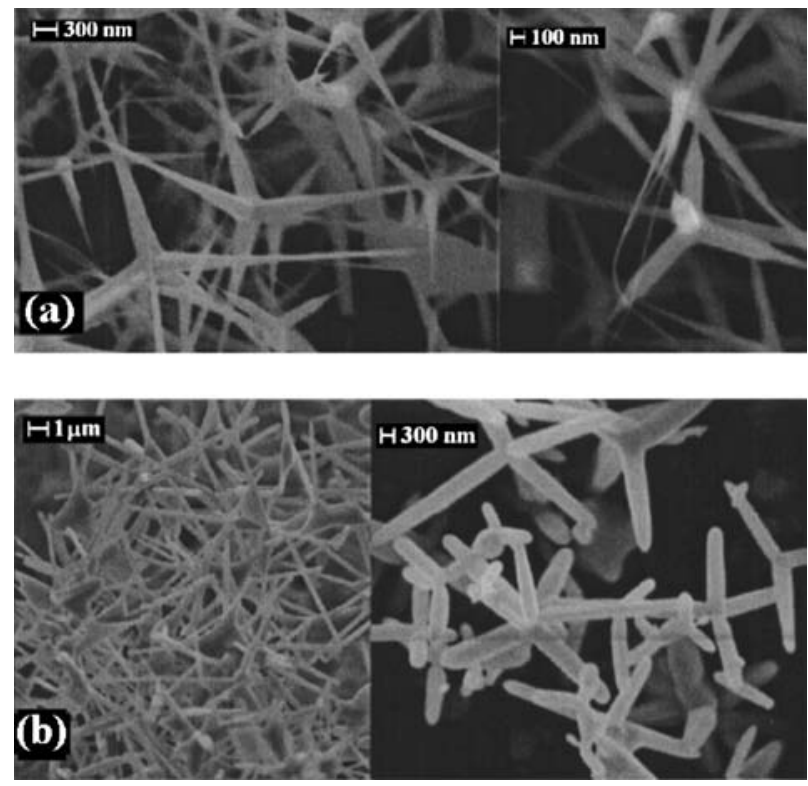

FIG. 1. Representative SEM images of (a) undoped $\mathrm{ZnO}$, (b) Mn diffusion doped $\mathrm{ZnO}$.

shown) results in larger increase of the size of the tetrapod structures. The XRD spectrum is shown in Fig. 2. For both doped and undoped samples, XRD data showed peaks corresponding to wurtzite $\mathrm{ZnO}$ only and no peak shifts were observed. No diffraction peaks from $\mathrm{Zn}$ or other impurities were detected. Mn content after Mn diffusion was examined by XRF. For diffusion at $600{ }^{\circ} \mathrm{C}, \mathrm{Mn}$ content was $8.4 \mathrm{~mol} \%$, while for diffusion at $800{ }^{\circ} \mathrm{C}$, Mn content was $2.2 \mathrm{~mol} \%$. Mn content in samples diffused at different temperature is determined not only by the diffusion coefficient which is expected to be higher at higher temperature, but also by other factors such as loss of sublimed Mn during pumping, which will be higher at $800^{\circ} \mathrm{C}$.

Figure 3 shows magnetic hysteresis $(\mathrm{M}-\mathrm{H})$ curves obtained at $5 \mathrm{~K}$ for the samples doped at 600 and $800^{\circ} \mathrm{C}$. The inset shows temperature dependence of the magnetization at the applied magnetic field of $20 \mathrm{kOe}$. Obtained Curie temperature of $\sim 50 \mathrm{~K}$ is significantly higher than $\sim 25 \mathrm{~K}$, observed for $\mathrm{Zn}_{0.9} \mathrm{Mn}_{0.1} \mathrm{O}$ thin films. ${ }^{3}$ Furthermore, the $\mathrm{Mn}$ doped $\mathrm{ZnO}$ tetrapod structures exhibit very high coercive field $\left(\sim 3500\right.$ Oe for sample doped at $800^{\circ} \mathrm{C}$ and $\sim 5500$ Oe for sample doped at $600^{\circ} \mathrm{C}$ ), which is about one order of magnitude higher than that reported for thin films. ${ }^{3}$ Similar

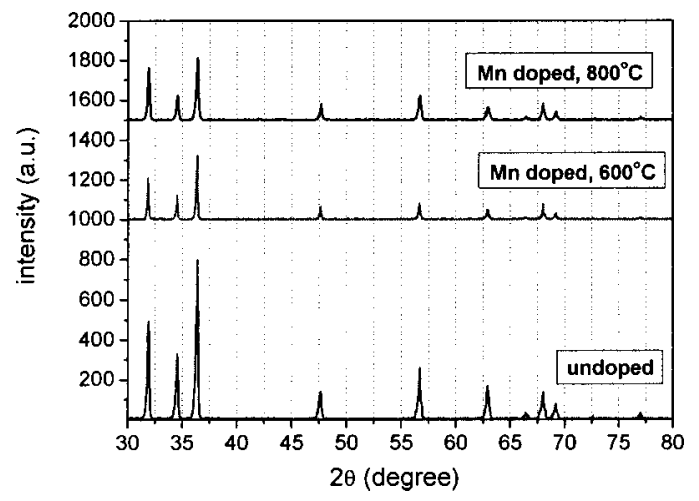

FIG. 2. XRD of undoped and $\mathrm{Mn}$ doped $\mathrm{ZnO}$ tetrapod structures. The

Furves have been vertically shifted to improve clarity.
Downloaded 30 Nov 2006 to 147.8.21.97. Redistribution subject to AIP license or copyright, see http://apl.aip.org/apl/copyright.jsp
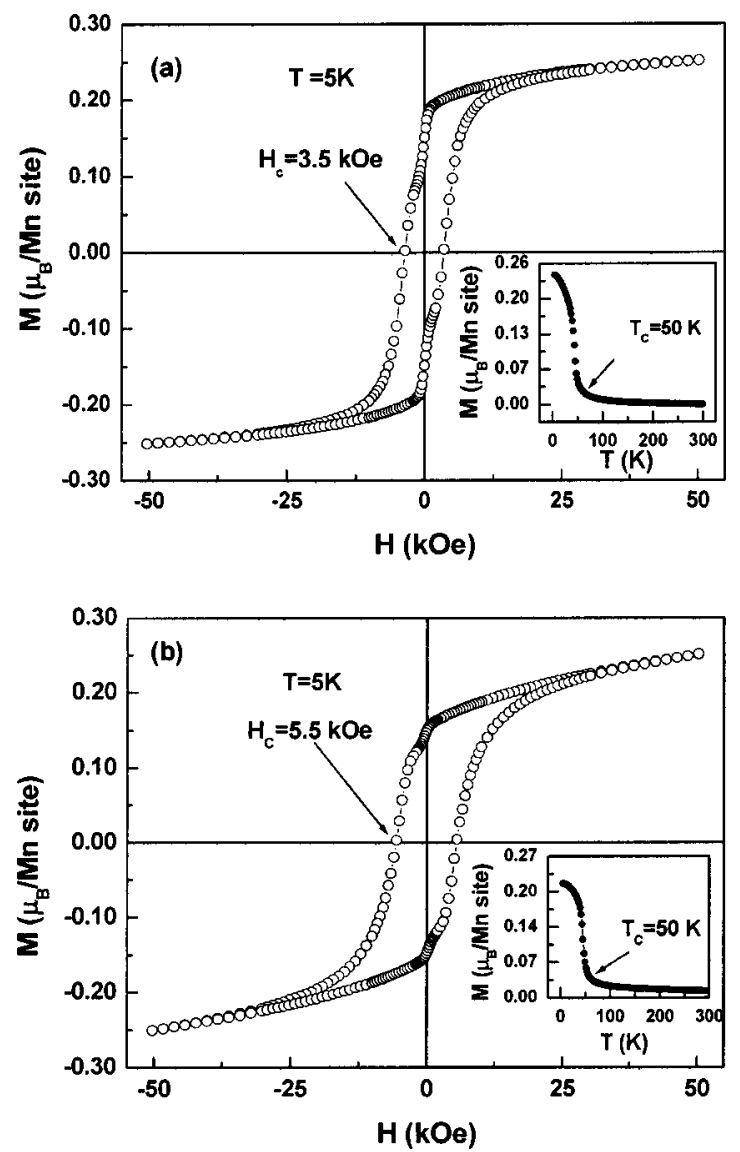

FIG. 3. (a) $\mathrm{M}$ vs. $\mathrm{H}$ curve at $5 \mathrm{~K}$ for $\mathrm{Mn}$ doped sample diffused at $800^{\circ} \mathrm{C}$. The inset shows magnetization vs temperature. (b) $\mathrm{M}$ vs. $\mathrm{H}$ curve at $5 \mathrm{~K}$ for Mn doped sample diffused at $600^{\circ} \mathrm{C}$. The inset shows magnetization vs temperature.

enhancement of the coercive field was observed in GaMnN nanowires. ${ }^{14}$ While GaMnN thin films typically exhibit coercive field below 100 Oe, GaMnN nanowires had coercive field in the range $620-1400$ Oe. ${ }^{14}$ The reasons for coercivity enhancement require further investigation. Another feature in Fig. 3 that should be noticed is that the $5 \mathrm{~T}$ magnetization for both samples is the same, $\sim 0.25 \mu_{B} / \mathrm{Mn}$, indicating that the magnetic states of the Mn ions seem to be independent of the doping up $8.4 \%$ in our nanostructured $\mathrm{ZnO}$ tetrapods.

The fact that the magnetization of $\sim 0.25 \mu_{B} / \mathrm{Mn}$ is much smaller than $\sim 5 \mu_{B}$ /Mn for a free $\mathrm{Mn}^{2+}$ ion with $S$ $=5 / 2$ and $g=2$, suggests that the dominant interactions between the $\mathrm{Mn}$ ions are antiferromagnetic, and the weak ferromagnetism could be ascribed to the nonlinear antiferromagnetic couplings (or canted ferromagnet). Actually the strong antiferromagnetic coupling has been observed in $\mathrm{Zn}_{0.64} \mathrm{Mn}_{0.36} \mathrm{O}$ epitaxial films, ${ }^{7}$ which resulted in a spin glass behavior and a magnetization of $0.20 \mu_{B} / \mathrm{Mn}(5 \mathrm{~T})$. By comparing with $\sim 0.17 \mu_{B} / \mathrm{Mn}$ obtained from the ferromagnetic epitaxial $\mathrm{Zn}_{1-x} \mathrm{Mn}_{x} \mathrm{O}$ epitaxial films, ${ }^{3}$ it is evident that it is significantly larger. It seems that data reported so far on $\mathrm{Mn}$ doped $\mathrm{ZnO}$ are not quite consistent, for example, besides the ferromagnetic behavior, ${ }^{3}$ behaviors of spin glass ${ }^{7}$ and paramagnet ${ }^{4}$ have also been observed. These discrepancies may be due to the different fabrication methods. Obviously, more detailed works are essential to understand the magnetic behaviors of these materials.

Figure 4 shows room temperature photoluminescence license or copyright, see http://apl.aip.org/apl/copyright.jsp 


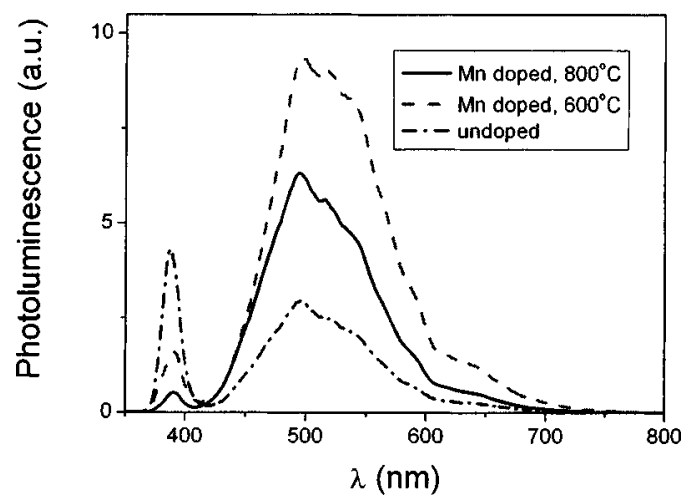

FIG. 4. Photoluminescence of undoped and $\mathrm{Mn}$ doped $\mathrm{ZnO}$ tetrapod structures.

(PL) of $\mathrm{ZnO}$ tetrapod structures with and without Mn diffusion doping. The PL spectrum of the undoped $\mathrm{ZnO}$ tetrapod nanorods shows characteristic UV emission and broad green emission, in agreement with previously reported results for $\mathrm{ZnO}$ tetrapod nanorods. ${ }^{12}$ It can be observed from Fig. 4 that Mn doping does not change the peak positions, which is in good agreement with the results reported in the literature. ${ }^{15,16}$ Mn doping is expected to cause reduction in the intensity of both $\mathrm{UV}^{16}$ and green emission. ${ }^{15,16}$ Since our samples are in the powder form of fluffy powder-like material, the ratio of UV to green emission should be compared instead of the absolute PL intensity since it is not possible to ensure that we probe the same amount of the material. It can be observed that both Mn doped samples show similar reduction in UV to green emission ratio, though UV emission is stronger in sample doped at $600{ }^{\circ} \mathrm{C}$. The reduction in emission intensity with $\mathrm{Mn}$ doping was attributed to increased nonradiative recombination processes. ${ }^{16}$ However, the relationship between the emission intensity and $\mathrm{Mn}$ concentration in the case of diffusion doping is likely to be complex due to the influence of annealing. The origin of green luminescence in $\mathrm{ZnO}$ is still not fully clear, but it is commonly believed that this emission originates from intrinsic defects in $\mathrm{ZnO}$, such as oxygen vacancy, ${ }^{17}$ donor-acceptor complexes ${ }^{18,19}$ and antisite oxygen. ${ }^{20}$ The intrinsic defects involved in green luminescence would be affected by annealing, so that the obtained PL spectrum after Mn doping would be affected both by annealing itself and by inclusion of $\mathrm{Mn}$.

It should also be pointed out that the diffusion doping will likely result in higher Mn concentration near the surface of $\mathrm{ZnO}$ tetrapod structures. Higher doping in the surface region was also found in nitrogen doped GaP nanobelts. ${ }^{21}$ The concentration of defects causing the green luminescence is also expected to be higher at the surface, as concluded from higher green luminescence from nanostructures with smaller diameter. ${ }^{9,10}$ For $\mathrm{Mn}$ doped $\mathrm{ZnO}$ nanocrystalline films, coreshell structure of nanocrystalline $(\mathrm{ZnO}$ core, interfacial region and $\mathrm{MnO}_{2}$ shell) was proposed to explain complete quenching of the green luminescence. However, in our work green luminescence can still be observed; the proposed explanation is not likely to be applicable to the tetrapod struc- tures studied in this work. Moreover, the possible existence of $\mathrm{Mn}$ oxides, $\mathrm{MnO}$ and $\mathrm{MnO}_{2}$, which cannot be excluded even though no secondary phases were detected by XRD, does not explain observed ferromagnetic properties. Both $\mathrm{MnO}$ and $\mathrm{MnO}_{2}$ are antiferromagnetic with Néel temperatures of 116 and $84 \mathrm{~K}$, respectively. ${ }^{3}$ Therefore, obtained results from XRD, PL and SQUID measurements suggest that $\mathrm{ZnMnO}$ alloy was formed, though $\mathrm{Mn}$ concentration is expected to be higher at the surface of tetrapod structures. Higher Mn content and/or presence of Mn oxides at the surface possibly contributed to the difference between observed magnetization and magnetization of a free $\mathrm{Mn}^{2+}$ ion.

To summarize, we have prepared $\mathrm{Mn}$ doped $\mathrm{ZnO}$ tetrapod structures by diffusion doping at temperatures 600 and $800^{\circ} \mathrm{C}$. The obtained samples have shown clear magnetic hysteresis at $5 \mathrm{~K}$. Curie temperature was determined to be $\sim 50 \mathrm{~K}$. The sample diffused at $600^{\circ} \mathrm{C}$ exhibited higher $\mathrm{Mn}$ concentration and higher remnant magnetization at $5 \mathrm{~K}$, as well as higher coercive field. Both samples exhibited very high coercive field, which is about one order of magnitude higher compared to values reported for $\mathrm{ZnO}: \mathrm{Mn}$ thin films.

The authors would like to thank Amy Wong and Wing Sang Lee for SEM and TEM measurements. H.L. and X.X.Z. have been supported by the Research Grants Council of the Hong Kong Special Administration Region, People's Republic of China (Project No. HKUST6165/01P).

${ }^{1}$ T. Dietl, H. Ohno, F. Matsukura, J. Cibert, and D. Ferrand, Science 287, 1019 (2000).

${ }^{2}$ K. Sato and H. Katayama-Yoshida, Physica E (Amsterdam) 10, 251 (2001).

${ }^{3}$ S. W. Jung, S.-J. An, G.-C. Yi, C. U. Jung, S.-I. Lee, and S. Cho, Appl. Phys. Lett. 80, 4561 (2002).

${ }^{4}$ X. M. Cheng and C. L. Chien, J. Appl. Phys. 93, 7876 (2003).

${ }^{5}$ S. W. Yoon, S.-B. Cho, S. C. We, S. Yoon, B. J. Suh, H. K. Song, and Y. J. Shin, J. Appl. Phys. 93, 7879 (2003).

${ }^{6}$ D. P. Norton, S. J. Pearton, A. F. Hebard, N. Theodoropoulou, L. A. Boatner, and R. G. Wilson, Appl. Phys. Lett. 82, 239 (2003).

${ }^{7}$ T. Fukumura, Z. Jin, M. Kawasaki, T. Shono, T. Hasegawa, and H. Koinuma, Appl. Phys. Lett. 78, 958 (2001).

${ }^{8}$ Z. W. Pan, Z. R. Dai, and Z. L. Wang, Science 291, 1947 (2001).

${ }^{9}$ M. H. Huang, Y. Wu, H. Feick, N. Tran, E. Weber, and P. Yang, Adv. Mater. (Weinheim, Ger.) 13, 113 (2001).

${ }^{10}$ B. D. Yao, Y. F. Chan, and N. Wang, Appl. Phys. Lett. 81, 757 (2002).

${ }^{11}$ H. Yan, R. He, J. Pham, and P. Yang, Adv. Mater. (Weinheim, Ger.) 15, 402 (2003).

${ }^{12}$ Y. Dai, Y. Zhang, Q. K. Li, and C. W. Nan, Chem. Phys. Lett. 358, 83 (2002).

${ }^{13}$ V. A. L. Roy, A. B. Djurišić, W. K. Chan, J. Gao, H. F. Lui, and C. Surya, Appl. Phys. Lett. 83, 141 (2003).

${ }^{14}$ F. L. Deepak, P. V. Vanitha, A. Govindaraj, and C. N. Rao, Chem. Phys. Lett. 374, 314 (2003).

${ }^{15}$ M. Liu, A. H. Kitai, and P. Mascher, J. Lumin. 54, 35 (1992).

${ }^{16}$ X. T. Zhang, Y. C. Liu, J. Y. Zhang, Y. M. Lu, D. Z. Shen, X. W. Fan, and X. G. Kong, J. Cryst. Growth 254, 80 (2003).

${ }^{17}$ K. Vanhausden, W. L. Warren, C. H. Seager, D. R. Tallant, J. A. Voigt, and B. E. Gnade, J. Appl. Phys. 79, 7983 (1996).

${ }^{18}$ S. A. Studenikin and M. Cocivera, J. Appl. Phys. 91, 5060 (2002).

${ }^{19}$ D. C. Reynolds, D. C. Look, and B. Jogai, J. Appl. Phys. 89, 6189 (2001).

${ }^{20}$ B. Lin, Z. Fu, and Y. Jia, Appl. Phys. Lett. 79, 943 (2001).

${ }^{21}$ H. W. Seo, S. Y. Bae, J. Park, H. Yang, M. Kang, S. Kim, J. C. Park, and S. Y. Lee, Appl. Phys. Lett. 82, 3752 (2003). 